\title{
The On-Freezing Phenomenon: Cognitive and Behavioral Aspects
}

\author{
Rita Moretti, Paola Torre, Rodolfo M. Antonello, Francesca Esposito, and Giuseppe Bellini \\ Medicina Clinica, Ambulatorio Complicanze Internistiche Cerebrali, Dipartimento Universitario Clinici di Scienze \\ Mediche Tecnologiche e Traslazionali, Università degli Studi di Trieste, Ospedale di Cattinara, Strada Fiume 447, 34149 Trieste, Italy
}

Correspondence should be addressed to Rita Moretti, moretti@univ.trieste.it

Received 14 November 2010; Revised 6 March 2011; Accepted 20 May 2011

Academic Editor: Irena Rektorova

Copyright ( $) 2011$ Rita Moretti et al. This is an open access article distributed under the Creative Commons Attribution License, which permits unrestricted use, distribution, and reproduction in any medium, provided the original work is properly cited.

Freezing of gait is a warning sign of Parkinson's disease. One could distinguish off-freezing, which is associated with dopaminergic therapy and to its titration, and it is clinically related to wearing-off phenomenon. Differently, the on-freezing phenomenon seems to be related to a neural disruption of the frontal-parietal-basal ganglia-pontine projections; clinically, it does not respond to therapy modifications or to different drug titration. In a group of patients with on-freezing, we have detected an alteration of focusing attention, an impairment of set-shifting, in addition to poor abstract reasoning and a reduction of planning. These aspects have been even more evident, when compared with the results obtained by a group of PD patients, without freezing.

\section{Introduction}

Freezing of gait (FOG) refers to transient episodes, usually lasting seconds, in which a patient is unable to initiate or continue locomotion, especially while turning, in stressful time-constrained situations and upon entrance into and through confined spaces such as doorways occurring on a background of relatively good ability to move [1-3] and is best described by patients as "feet get glued to the ground." FOG typically appears when a patient is forced to change his normal, automatic gait pattern or speed (at tight quarters, reaching destination) or when responding to stressful situations [4].

Freezing of gait is common in Parkinson's disease (PD), with increasing prevalence as the disease progresses $[1,2,5-$ 7], but it has been commonly reported in pathologically proven progressive supranuclear palsy (PSP) and vascular parkinsonism $[8,9]$. Although not present in all patients, freezing is perhaps the most debilitating symptom of Parkinson's disease as it may lead to falls, a decrease in quality of life, and loss of independence. Nearly one third of Parkinson's disease patients experience some type of freezing episode $[1,10]$.

To be precise, two types of freezing of gait have been recognized in patients affected by Parkinson's disease, taking L-Dopa. The most common is an "off-"freezing of gait, which can be improved with L-Dopa or dopaminergic treatment, such as apomorphine $[4,11]$. "Off-"freezing appears during an "off" state, when the patient is generally bradykinetic and rigid.

In contrast, "on-"freezing is characterized by a worsening of symptoms as the dose of L-Dopa is increased and by a general improvement as the dose is decreased or, better said, modulated. Patients who experience "on-"FOG frequently report that they walk better before the first morning dose of L-Dopa, or at their "off" state. On-freezing lasts for short times: generally few seconds, at most several minutes. The on-freezing of gait is related to abnormal execution of complex motor tasks such as repetitive, simultaneous, or sequential motor acts [12-14]. Recent evidence has suggested other possible factors that may contribute. In their more recent work, Giladi et al. [15] argue that FOG must have a different pathophysiology than typical motor symptom, since other motor issues are positively influenced by dopaminergic medication, while freezing remains unresponsive.

Different authors suggested that the primary underlying abnormality might be related to the inability to deliver or hold a preprogrammed, continuous, and complex motor act, in response to an established and correct internal plan of action $[12,13]$. Increased stride-to-stride variability has recently been identified before FOG (compared with Parkinson's disease patients without FOG) during a $20 \mathrm{~m}$ 
TABle 1: (a) Specific scores of the two groups, (b) specific scores of the two groups.

(a)

\begin{tabular}{|c|c|c|c|c|}
\hline & Group A & Group B & Group A & Group B \\
\hline & \multicolumn{2}{|c|}{ in on } & \multicolumn{2}{|c|}{ in off } \\
\hline Freezing when walking (UPDRS II) & $2.7 \pm 1.2$ & $1.2 \pm 0.4$ & $2.9 \pm 0.7$ & $3.1 \pm 0.3$ \\
\hline Walking (UPDRS II) & $2.4 \pm 0.5$ & $0.9 \pm 0.7$ & $2.5 \pm 0.2$ & $2.7 \pm 0.1$ \\
\hline Gait (UPDRS III) & $2.5 \pm 0.3$ & $1.1 \pm 0.9$ & $2.6 \pm 0.2$ & $2.9 \pm 0.4$ \\
\hline
\end{tabular}

(b)

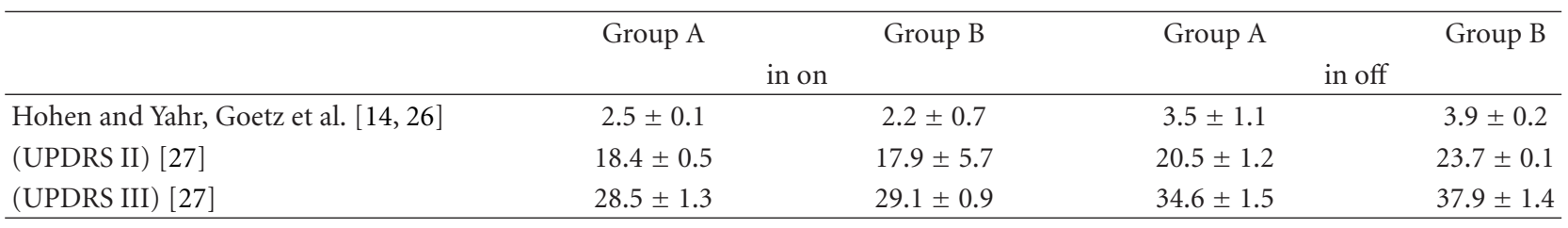

"stand up and go" walking task [16]; in this work, it has been demonstrated that the ability to regulate stride-to-stride timing during gait is severely impaired in FOG patients compared with other individuals with Parkinson's disease [16]. Parkinson's disease patients with FOG also display altered timing and, specifically, premature muscle activation and termination patterns before a freezing episode, leading to an abnormally long stance phase [17-19]. Perception may be the most important alternate mechanisms to consider. While perceptual influences associated with freezing are rarely considered, Parkinson's disease patients are profoundly influenced by awareness of their body (relative to environment) $[10,16,20,21]$ and by space perception $[22,23]$. Impaired integration of vision with spatial memory altered recovery might help FOG patients in adapting to confined spaces [24].

Considering that the "on-FOG" is a complex phenomenon, with an obscure pathogenesis and an even obscurer clinical history $[4,25]$, we hypothesized that PD patients, presenting the on-freezing, might be cognitively well differentiated from the other clinical subtypes of $\mathrm{PD}$, without onFOG.

Therefore, several patients were chosen, presenting onfreezing as an early manifestation of $\mathrm{PD}$, and their cognitive and behavioral scores on different specific tasks were compared with those obtained by patients with PD, without onfreezing, but manifesting off-freezing. The clinical and neuropsychological followup was done in 12 months.

\section{Method}

2.1. Subjects. The study included 73 patients ( 40 men and 33 women) suffering from idiopathic PD [29]. Three patients did not want to be tested and therefore did not participate to the followup. All the other patients could be fully studied (mean age 68.4 \pm 7.12 years, range $=60-78$ years; average age at onset $=63.22 \pm 3.12$ years, range $=62-67$ years $)$. The patients suffered for a mean of $3.56 \pm 2.75$ years from $P D$ and had been treated with dopaminergic preparations (L-Dopa and dopamine-agonists).

All the patients fulfilled the criteria of idiopathic PD [29].
Group A enclosed 38 cases of PD, who presented onfreezing, as referred by caregivers, and confirmed by personal trainers and by their neurologist (three patients of this group refused to complete the study). On-freezing was verified historically and by an actual gait assessment at on and at off (see Table 1(a)). Group B was composed by 35 Parkinson's disease patients, without on-freezing (but with off-freezing).

Patients were evaluated in off- and on-pharmacological states (see Table 1(b)). All the patients responded to LDopa. The mean L-Dopa equivalent dosage was $1215 \pm$ $321.34 \mathrm{mg} /$ day. 43 patients received dopamine agonists during their cure; only 27 began their therapy with dopamineagonists.

All the subjects were right handed $(+22.34 \pm 1.32)$ according to the Briggs' and Nebes' handedness test [28]. Their average educational levels, represented by school years, are of $11.34 \pm 5.67$ years.

Patients were divided into two homogenous groups, matched for age and education levels. Patients have been followed for one year. 33 patients of Group A and 29 patients of Group B completed the followup.

Neuroimaging studies were assessed, including magnetic resonance imaging (in 32 patients, 17 in group A and 15 in group B) and CT scans (in all the patients). Neither signs of normal pressure hydrocephalus, nor ischemic infarctions or lacunar infarcts have been found.

The trial was conducted in accordance with the Declaration of Helsinki and with the Ethics Guidelines of the Institute.

2.2. Outcome Measures. The general cognitive profile was tested by this battery of tests: Stroop Test [30], considering as subscores the time of execution and the number of mistakes, Raven Standard Progressive Matrices [31], considering as sub-scores the time of execution and the number of correct answers, Digit span backwards and forwards [32], the oral version of the Trail Making, part A [33] considering as subscores the time of execution and the number of mistakes, word fluency, considering three minutes of phonological task [32], Proverbs' Interpretation Test [34], Ten-Point Clock 
TABLE 2: Synopsis of the baseline characteristics of the two groups.

\begin{tabular}{lcc}
\hline & Group A & Group B \\
\hline Age & $68.31 \pm 4.12$ & $65.45 \pm 1.23$ \\
Average age at onset & $63.78 \pm 1.56$ & $63.01 \pm 1.21$ \\
Illness duration & $3.12 \pm 1.12$ & $3.87 \pm 3.5$ \\
Mean L-Dopa & $1212 \pm 121.34$ & $1200 \pm 621.45$ \\
equivalent dosage & $\mathrm{mg} /$ day & $\mathrm{mg} /$ day \\
Handedness test [28] & $+23.10 \pm 1.50$ & $+20.50 \pm 2.30$ \\
Average educational & $11.11 \pm 3.45$ years & $13.11 \pm 5.20$ years \\
levels (school years) & & \\
\hline
\end{tabular}

Test [35], verbal retrieval [36], and Clinical Insight [37]. The patients underwent a Cornell evaluation for depression [38]. In particular, we employed the item: "anxiety" from the Cornell's scale, with a maximum score of 8 , which indicate a maximum degree of anxiety, as an adjunctive informative parametric score, of mood.

All the patients have been tested (as far as neuropsychological measures are concerned) in on-pharmacological state; so far, all the patients should have the most convincing performances; in fact, no off-freezing has been detected. On the contrary, on-freezing, in group A, appears frequently during the test.

2.3. Statistical Analyses. Statistical analyses were performed using the Statistical Package for the Social Sciences (SPSS, version 13.0). Within-group changes from baseline to 12 months were tested using the Wilcoxon Signed Ranks test, due to the small number of patients enrolled. Betweengroup comparisons of changes from baseline were tested using the Wilcoxon two-sample test. This was done for the overall scores for each efficacy variable. Spearman's rho correlation, 2-tailed analyses were performed among digit span (forward and backward), phonological fluency, proverbs' interpretation and clock execution, and between clinical insight and depression scores. Results are presented as mean changes from baseline with standard deviations, and $P$-values are presented where appropriate.

\section{Results}

A synopsis of the characteristics of the two groups has been reported in Table 2. Table 3 reports the results obtained at baseline by the two groups. Group A manifested transient episodes, usually lasting seconds. During this kind of episode, a patient is unable to initiate a sentence or talk as he did before. At the end of the episode, usually after few seconds, he starts again to talk and to express his opinions, beginning from the point when he was interrupted. We define these episodes as "freezing of thought or freezing of speech."

According to a Wilcoxon two-sample test, Group A (onFOG PD) had lower scores than Group B (PD patients) in the digit span forward task $(P<0.05)$; they made more mistakes in the Trail Making test $(P<0.01)$, in Proverbs' Interpretation task $(P<0.01)$, in the Stroop Test $(P<0.01)$ (execution time and number of mistakes), and in the TenPoint Clock Test $(P<0.01)$. However, Group A scored higher than Group B in the phonological task $(P<0.01)$. The two groups did equally well in the digit span backward task, in the Trail Making Test (considering time of execution), in the Raven Matrices (time and number of correct answers), and in the memory recall tasks. Group B scored as more depressed than Group A on the Cornell's Score $(P<0.01)$, but patients from Group B reported greater introspection in their clinical situation $(P<0.01)$ on the Cornell's Score subitem. There was no difference among the two groups, when considering the anxiety scores (subitem of the Cornell's Score).

Table 4 reports the results obtained at 12 months by the two groups. Within-group changes from baseline to 12 months were tested using the Wilcoxon Signed Ranks test; between-group comparisons of changes from baseline were tested using the Wilcoxon two-sample test. Group A (on-FOG PD) scored worse, over baseline according to a Wilcoxon Signed Ranks test, in the digit span backward $(P<0.05)$, in Proverbs' Interpretation Test $(P<0.05)$ and in the Stroop test $(P<0.05)$ (time of execution and number of mistakes). Group B (PD) scored worse over baseline in the digit span backward test $(P<0.05)$ and in the Cornell's Scale $(P<0.01)$. Group B improved in the Proverbs' Interpretation Test $(P<0.05)$. Group A scored worse than Group B, according to a Wilcoxon two-sample test, in the digit span forward task $(P<0.05)$ and made more mistakes in the Trail Making test $(P<0.01)$, in Proverbs' Interpretation task $(P<0.01)$; they scored more poorly in the Stroop Test $(P<0.01)$ (execution time and number of mistakes) and in the Ten-Point Clock Test $(P<$ 0.01). Like at baseline, Group A scored better than Group $\mathrm{B}$ in the phonological task $(P<0.01)$. Group B reported being more depressed than Group A, as demonstrated by the Cornell's Score $(P<0.01)$, and continued to show greater introspection in the clinical situation $(P<0.01)$, on the Clinical insight rating Scale (CIR). The anxiety score for Group A was lower than that of group B $(P<0.05)$.

Only Group A patients manifested freezing of thought, freezing of speech, or both.

Spearman's rank correlation analyses indicated that there was a significant correlation between the digit span scores and the proverbs' interpretation scores $(r=0.78, P<0.01$; $r=0.81, P<0.01$, resp.) and between the digit span scores and the Ten-Point Clock Test $(r=0.69, P<0.05 ; r=0.72$, $P<0.01$, resp.); no correlation was found between digit span scores and the phonological fluency. A positive correlation between CIR and Cornell's Scale $(r=0.88, P<0.01)$ was found.

\section{Discussion}

Freezing of gait (FOG), as stated previously, is a complication of PD. Iansek et al. [39] suggested that FOG during walking was possibly due to the presence of the "sequence effect" (gradual step to step reduction), in combination with an overall reduced step length which, if small enough, would eventually lead to freezing. That hypothesis was based on the duality of basal ganglia function and malfunction in 
TABLe 3: A comparison between the two groups, at baseline.

\begin{tabular}{|c|c|c|c|}
\hline Items & Group A & Group B & $P$ \\
\hline Phonological fluency & $23.12 \pm 9.10$ & $12.12 \pm 2.11$ & $P<0.01$ \\
\hline Intrusion mistakes & $8.90 \pm 2.34$ & $2.34 \pm 0.12$ & $P<0.01$ \\
\hline Digit span forward & $3.34 \pm 0.50$ & $4.75 \pm 1.12$ & $P<0.05$ \\
\hline Digit span backward & $3.20 \pm 1.07$ & $3 \pm 0.76$ & ns \\
\hline Trail making oral; time (sec.) & $37.33 \pm 6.33$ & $34.65 \pm 3.98$ & ns \\
\hline Trail making oral; mistakes & $7.98 \pm 3.4$ & $4.10 \pm 0.40$ & $P<0.01$ \\
\hline Freezing of thoughts & $1 \pm 0.0$ & 0.0 & \\
\hline Freezing of language & $1 \pm 0.0$ & 0.0 & \\
\hline CIR & $3.23 \pm 0.43$ & $0.98 \pm 0.12$ & $P<0.01$ \\
\hline Proverbs' Interpretation (correct answers) & $4.76 \pm 2.65$ & $14.23 \pm 2.45$ & $P<0.01$ \\
\hline Raven; time (min.) & $35.53 \pm 4.30$ & $34.12 \pm 7.20$ & ns \\
\hline Raven; (correct answers) & $21.34 \pm 4.24$ & $21.5 \pm 4.04$ & ns \\
\hline Stroop; time (sec.) & $57.91 \pm 39.56$ & $22.38 \pm 10.53$ & $P<0.01$ \\
\hline Stroop; mistakes & $5 \pm 4.23$ & $1.23 \pm 2.25$ & $P<0.01$ \\
\hline Retrieval of a story; (correct answers) & $9.38 \pm 5.60$ & $10.13 \pm 4.64$ & ns \\
\hline Ten-Point Clock Test & $1.88 \pm 1.25$ & $3.5 \pm 0.53$ & $P<0.01$ \\
\hline Cornell's Scale & $7.75 \pm 2.76$ & $12.5 \pm 3.59$ & $P<0.01$ \\
\hline Anxiety score & $3.2 \pm 1.71$ & $2.93 \pm 2.78$ & ns \\
\hline
\end{tabular}

TABle 4: A comparison between the two groups, at 12 months.

\begin{tabular}{|c|c|c|c|c|c|}
\hline Items & Group A & Over baseline & Group B & Over baseline & $P$ A versus $\mathrm{B}$ \\
\hline Phonological fluency & $-1.23 \pm 0.20$ & ns & $+2.70 \pm 0.40$ & ns & $P<0.01$ \\
\hline Intrusion mistakes & $+3.45 \pm 0.34$ & $P<0.05$ & $+0.23 \pm 0.20$ & ns & $P<0.01$ \\
\hline Digit span forward & $-0.40 \pm 0.10$ & ns & $-0.50 \pm 0.10$ & ns & $P<0.05$ \\
\hline Digit span backward & $-1.10 \pm 0.20$ & $P<0.05$ & $-1.23 \pm 0.10$ & $P<0.05$ & ns \\
\hline Trail making oral; time (sec.) & $+3.20 \pm 1.10$ & ns & $+3.10 \pm 1.80$ & ns & ns \\
\hline Trail making oral; mistakes & $+1.80 \pm 0.20$ & $P<0.05$ & $+0.70 \pm 0.20$ & ns & $P<0.01$ \\
\hline Freezing of thoughts & $1 \pm 0.0$ & & 0.0 & & \\
\hline Freezing of language & $1 \pm 0.0$ & & 0.0 & & \\
\hline CIR & $+0.70 \pm 0.91$ & ns & $+0.69 \pm 0.39$ & ns & $P<0.01$ \\
\hline Proverbs' Interpretation (correct answers) & $-1.30 \pm 0.50$ & $P<0.05$ & $+2.30 \pm 0.50$ & $P<0.05$ & $P<0.01$ \\
\hline Raven; time (min.) & $+1.50 \pm 0.30$ & ns & $+1.70 \pm 0.30$ & ns & ns \\
\hline Raven (correct answers) & $+1.40 \pm 0.24$ & ns & $-0.50 \pm 0.04$ & ns & ns \\
\hline Stroop; time (sec.) & $+7.20 \pm 0.50$ & $P<0.05$ & $+2.90 \pm 4.20$ & ns & $P<0.01$ \\
\hline Stroop; mistakes & $+2.10 \pm 0.40$ & $P<0.05$ & $+1.70 \pm 0.90$ & ns & $P<0.01$ \\
\hline Retrieval of a story (correct answers) & $+1.30 \pm 0.20$ & ns & $-0.98 \pm 0.60$ & ns & ns \\
\hline Ten-Point Clock Test & $-0.20 \pm 0.50$ & ns & $+0.40 \pm 0.20$ & ns & $P<0.01$ \\
\hline Cornell's Scale & $+1.20 \pm 0.60$ & ns & $+4.50 \pm 0.90$ & $P<0.01$ & $P<0.01$ \\
\hline Anxiety score & $+0.10 \pm 0.21$ & ns & $+1.20 \pm 0.12$ & $P<0.05$ & $P<0.05$ \\
\hline
\end{tabular}

Parkinson's disease in the elaboration of automatic movement in conjunction with the supplementary motor area. It has been suggested (see data and Literature in [40]) that the basal ganglia maintains cortically selected motor set, in the supplementary motor area, and provides internal cues to the supplementary motor area, in order to enable each submovement, to be correctly linked together [41]. Iansek et al. [39] examined the sequence effect in FOG subjects and found that, contrary to hypokinesia, the sequence effect did not respond to medication or attention strategies. It did disappear with the use of external cues in that study; however, no evidence was provided to support the hypothesis that FOG was due to the presence of the sequence effect (gradual step to step reduction) in combination with an overall reduced step length.

FOG leads to difficulties in set shifting [42] while other executive domains, such as working memory, verbal fluency, and planning/organization abilities have weaker 
associations [43-47]. Thus, it would appear that the neural network underlying FOG in PD may overlap with the network controlling processes of set shifting [47].

The results obtained in our work can be summarized as follows: two homogenous groups of patients, with Parkinson's disease, followed for three years by a dedicated neurologist, have been compared. There is overall $\mathrm{PD}$ duration of 3-4 years since diagnosis. Patients have been tested in on-pharmacological state; in this condition, only Group A manifested on-freezing, Group B did not evidence it. Effectively, Group A (and therefore the matched cases selected for Group B) had high UPDRS and $H$ and $Y$ scores and L-Dopa equivalent dose over $1000 \mathrm{mg} /$ day, clear hallmarks of advanced stage PD, which does not usually correspond to 3-4 year PD duration. It was not our intention to select a subgroup of patients with a worse form of PD, but in fact, that it is the result: it seems that on-freezing and offprecocious phenomena [46] are selected forms of an intriguing and rather complicated form of PD; the former case is not sensitive to dopamine adjustment; the latter has good response to therapy modulation, almost in precocious time.

Our study demonstrated that the cognitive and behavioral profile of these patients vary from those of patients with Parkinson's disease, who did not suffer from on-freezing of gait. The results indicated that patients with Parkinson's disease and who did present freezing of gait could not focus their attention on a given task, as indicated by the worse scores obtained in the digit span forward task and in the Trail Making test. They could not implement a correct verbal logical judgment (as showed by the low score obtained in the Proverbs' Interpretation task). They showed worse performances in executive function (as demonstrated by the Stroop test and by the Ten-Point Clock test). Contradictorily, our patients with on-freezing produced much more words in the phonological task than patients who suffered from Parkinson's disease without freezing. When examined more closely, their verbal production contained a higher percentage of intrusion words (semantically related to the produced words, most of the time) than that of Parkinson's patients without freezing. Patients with off-freezing are more depressed and with major introspection and insight than patients with on-freezing.

Our results indicate that "induced" verbal fluency is qualitatively compromised in on-freezing patients with Parkinson's disease. Moreover, these patients altered the focusing mechanism of selective attention, of the abstract reasoning, judgment, and of the executive function, as well as they showed a lack of insight in their clinical situation. In our study, we observed that while the patients with the onfreezing phenomenon manifest sudden brisk interruption of thought or of speech, a simple provoked noise (even a question formulated by the investigator) shortens the time of them and accelerates the "rescue" of the cognitive process. These considerations support what has been said about motor blocks in PD. The novel external stimulus, represented by the noise or by the examiner's voice, seems to "oblige" the cortex to process the novel stimulus. The consequential results are the prosecution of the task.
Anatomical localization of the processes underlying attentive control, utilizing functional magnetic resonance imaging in PD patients, has identified that attentive control is related to increased activation of the ventrolateral prefrontal cortex [48]. In addition, works in healthy controls have proposed that the reward feedback mechanisms involved in switching attention relate to regions within the orbitofrontal cortex [49]. On-freezing (motor aspects, of course) has been reported to improve with the applications of external rhythmic stimuli, including metronome stimulation or application of weak electromagnetic fields [50]. Thereby, the use of external attentive strategies may allow movement to be mediated by less automatic and more conscious attentive motor control processes (frontal cortical regions), which may be less impaired than the automatic process (subcortical basal-ganglia-frontal neural pathway) ([39, 51, 52]). Chronic on-line control exerted by the subcortical circuits might be disrupted in on-freezing of gait patients, with an alteration of a presumed "salient map" representation as a consequence. Attention should be elicited with novel external stimuli, in order to implement the cortical parietal circuits: when the cortex actively participates, the patient can reapproach the task and the stop is abolished [53-55]. We hypothesize that the control exerted by the frontal-caudate-pulvinar circuits might be disrupted in on-freezing; this circuit is mainly involved in verifying the semantic acceptability of the linguistic production and in the so-called language planning loop $[56,57]$. This hypothesis might explain the intrinsic difficulty showed by on-FOG patients to suppress their "intrusive verbal thoughts" in phonological tasks [58].

To speculate, one might say that on-freezing is not at all a motor variance of Parkinson's disease, but rather a complex, wide-extended, syndrome, that involves gait (as one of the most evident aspects), as well as cognition and behavior.

\section{References}

[1] N. Giladi, D. McMahon, S. Przedborski et al., "Motor blocks in Parkinson's disease," Neurology, vol. 42, no. 2, pp. 333-339, 1992.

[2] N. Giladi, R. Kao, and S. Fahn, "Freezing phenomenon in patients with parkinsonian syndromes," Movement Disorders, vol. 12, no. 3, pp. 302-305, 1997.

[3] N. Giladi and S. Fahn, "Freezing phenomenon, the fifth cardinal sign of parkinsonism," in Progress in Alzheimer's and Parkinson's Diseases, A. Fisher, I. Hanin, and M. Yoshida, Eds., pp. 329-335, Plenum Press, New York, NY, USA, 1998.

[4] N. Giladi, "Freezing of gait. Clinical overview," in Gait Disorders. Advances in Neurology, E. Ruzicka, M. Hallett, and J. Jankovic, Eds., vol. 87, pp. 191-197, Lippincott Williams \& Wilkins, Philadelphia, Pa, USA, 2001.

[5] P. Lamberti, S. Armenise, V. Castaldo et al., "Freezing gait in Parkinson's disease," European Neurology, vol. 38, no. 4, pp. 297-301, 1997.

[6] S. Hassin-Baer, P. Sirota, A. D. Korczyn et al., "Clinical characteristics of neuroleptic-induced parkinsonism," Journal of Neural Transmission, vol. 108, no. 11, pp. 1299-1308, 2001.

[7] S. Fahn, "Parkinsonism," in Merritt's Textbook of Neurology, L. Rowland, Ed., pp. 123-137, Lea \& Febiger, Philadelphia, Pa, USA, 1994. 
[8] H. Narabayashi, H. Imai, and M. Yokochi, "Cases of pure akinesia without rigidity and tremor and with no effect by L-Dopa therapy," in Advances in Parkinsonism, W. Birkmyer and O. Horniekiewicz, Eds., pp. 335-342, Roche, Basel, Switzerland, 1976.

[9] H. Imai, H. Narabayashi, and E. Sakata, "Pure akinesia' and the later added supranuclear ophthalmoplegia," Advances in Neurology, vol. 45, pp. 207-212, 1987.

[10] Q. J. Almeida and C. A. Lebold, "Freezing of gait in Parkinson's disease: a perceptual cause for a motor impairment?" Journal of Neurology, Neurosurgery and Psychiatry, vol. 81, no. 5, pp. 513-518, 2010.

[11] G. Linazasoro, "The apomorphine test in gait disorders associated with Parkinsonism," Clinical Neuropharmacology, vol. 19, no. 2, pp. 171-176, 1996.

[12] C. D. Marsden, "Slowness of movement in Parkinson's disease," Movement Disorders, vol. 4, no. 1, pp. S26-S37, 1989.

[13] R. Schwab, A. England, and E. Peterson, "Akinesia in Parkinson's disease," Neurology, vol. 9, pp. 65-72, 1959.

[14] M. M. Hoehn and M. D. Yahr, "Parkinsonism: onset, progression and mortality," Neurology, vol. 17, no. 5, pp. 427-442, 1967.

[15] N. Giladi, V. Huber-Mahlin, T. Herman, and J. M. Hausdorff, "Freezing of gait in older adults with high level gait disorders: association with impaired executive function," Journal of Neural Transmission, vol. 114, no. 10, pp. 1349-1353, 2007.

[16] J. M. Hausdorff, J. D. Schaafsma, Y. Balash, A. L. Bartels, T. Gurevich, and N. Giladi, "Impaired regulation of stride variability in Parkinson's disease subjects with freezing of gait," Experimental Brain Research, vol. 149, no. 2, pp. 187-194, 2003.

[17] A. Nieuwboer, W. De Weerdt, R. Dom et al., "Plantar force distribution in Parkinsonian gait: a comparison between patients and age-matched control subjects," Scandinavian Journal of Rehabilitation Medicine, vol. 31, no. 3, pp. 185-192, 1999.

[18] A. Nieuwboer, R. Dom, W. De Weerdt, K. Desloovere, S. Fieuws, and E. Broens-Kaucsik, "Abnormalities of the spatiotemporal characteristics of gait at the onset of freezing in Parkinson's disease," Movement Disorders, vol. 16, no. 6, pp. 1066-1075, 2001.

[19] A. Nieuwboer, R. Dom, W. De Weerdt, K. Desloovere, L. Janssens, and V. Stijn, "Electromyographic profiles of gait prior to onset of freezing episodes in patients with Parkinson's disease," Brain, vol. 127, no. 7, pp. 1650-1660, 2004.

[20] Q. J. Almeida, J. S. Frank, E. A. Roy et al., "An evaluation of sensorimotor integration during locomotion toward a target in Parkinson's disease," Neuroscience, vol. 134, no. 1, pp. 283293, 2005.

[21] Q. J. Almeida, J. S. Frank, E. A. Roy, A. E. Patla, and M. S. Jog, "Dopaminergic modulation of timing control and variability in the gait of Parkinson's disease," Movement Disorders, vol. 22, no. 12, pp. 1735-1742, 2007.

[22] A. M. Johnson, Q. J. Almeida, C. Stough, J. C. Thompson, R. Singarayer, and M. S. Jog, "Visual inspection time in Parkinson's disease: deficits in early stages of cognitive processing," Neuropsychologia, vol. 42, no. 5, pp. 577-583, 2004.

[23] C. Gurvich, N. Georgiou-Karistianis, P. B. Fitzgerald, L. Millist, and O. B. White, "Inhibitory control and spatial working memory in Parkinson's disease," Movement Disorders, vol. 22, no. 10, pp. 1444-1450, 2007.

[24] A. C. Lee and J. P. Harris, "Problems with perception of space in Parkinson's disease: a questionnaire study," NeuroOphthalmology, vol. 22, no. 1, pp. 1-15, 1999.
[25] C. D. Marsden and J. A. Obeso, "The functions of the basal ganglia and the paradox of stereotaxic surgery in Parkinson's disease," Brain, vol. 117, no. 4, pp. 877-897, 1994.

[26] C. G. Goetz, W. Poewe, O. Rascol et al., "Movement disorder society task force report on the hoehn and yahr staging scale: status and recommendations," Movement Disorders, vol. 19, no. 9, pp. 1020-1028, 2004.

[27] S. Fahn, R. L. Elton, and The Members of the UPDRS Development Committee, "The unified Parkinson's disease rating scale," in Recent Developments in Parkinson's Disease, S. Fahn, C. D. Marsden, D. B. Calne, and M. Goldstein, Eds., vol. 2, pp. 153-163, Macmillan Healthcare, Florham Park, NJ, USA, 1987.

[28] G. G. Briggs and R. D. Nebes, "Patterns of hand preference in a student population," Cortex, vol. 11, no. 3, pp. 230-238, 1975.

[29] A. J. Hughes, S. E. Daniel, L. Kilford, and A. J. Lees, "Accuracy of clinical diagnosis of idiopathic Parkinson's disease: a clinico-pathological study of 100 cases," Journal of Neurology Neurosurgery and Psychiatry, vol. 55, no. 3, pp. 181-184, 1992.

[30] J. R. Stroop, "Studies of interference in serial verbal reactions," Journal of Experimental Psychology, vol. 18, no. 6, pp. 643-662, 1935.

[31] J. C. Raven, Standard Progressive Matrices, Lewis, London, UK, 1938.

[32] D. Wechsler, Wechsler Adult Intelligence Scale Manual-R, Grune \& Stratton, New York, NY, USA, 1981.

[33] R. M. Reitan and D. Wolfson, The Halstead Reitan Neuropsychological Test Battery; Theory and Clinical Interpretation, Neuropsychological Press, Tucson, Ariz, USA, 1985.

[34] D. R. Gorham, The Proverbs Test, Psychol Rep Monogr, Missoula, Mont, USA, 1956.

[35] P. J. Manos and R. Wu, "The ten point clock test: a quick screen and grading method for cognitive impairment in medical and surgical patients," International Journal of Psychiatry in Medicine, vol. 24, no. 3, pp. 229-244, 1994.

[36] D. Wechsler, "A standardized memory scale for clinical use," The Journal of Psychology, vol. 19, pp. 87-97, 1945.

[37] B. R. Ott, G. Lafleche, W. M. Whelihan, G. W. Buongiorno, M. S. Albert, and B. S. Fogel, "Impaired awareness of deficits in Alzheimer's disease," Alzheimer Disease and Associated Disorders, vol. 10, no. 2, pp. 68-76, 1996.

[38] G. S. Alexopoulos, R. C. Abrams, R. C. Young, and C. A. Shamoian, "Cornell scale for depression in dementia," Biological Psychiatry, vol. 23, no. 3, pp. 271-284, 1988.

[39] R. Iansek, F. Huxham, and J. McGinley, "The sequence effect and gait festination in parkinson disease: contributors to freezing of gait?" Movement Disorders, vol. 21, no. 9, pp. 14191424, 2006.

[40] R. Moretti, P. Torre, and R. M. Antonello, Basal Ganglia: Functional and Organic Roles in Behaviour and Cognition, Nova Editorial, New York, NY, USA, 2009.

[41] R. Iansek, J. L. Bradshaw, J. G. Phillips, R. Cunnington, and M. E. Morris, "Interaction of the basal ganglia and supplementary motor area in the elaboration of movement," in Motor Control and Sensorimotor Integration, D. J. Glencross and J. P. Piek, Eds., pp. 37-59, Elsevier Science, Amsterdam, The Netherlands, 1995.

[42] S. J. G. Lewis and R. A. Barker, "A pathophysiological model of freezing of gait in Parkinson's disease," Parkinsonism and Related Disorders, vol. 15, no. 5, pp. 333-338, 2009.

[43] N. Fabre, C. Brefel, U. Sabatini et al., "Normal frontal perfusion in patients with frozen gait," Movement Disorders, vol. 13, no. 4, pp. 677-683, 1998.

[44] R. Camicioli, B. S. Oken, G. Sexton, J. A. Kaye, and J. G. Nutt, "Verbal fluency task affects gait in Parkinson's disease with 
motor freezing," Journal of Geriatric Psychiatry and Neurology, vol. 11, no. 4, pp. 181-185, 1998.

[45] H. Matsui, F. Ukada, T. Miyoshi et al., "Three-dimensional stereotactic surface projection study of freezing of gait and brain perfusion image in Parkinson's disease," Movement Disorders, vol. 20, no. 10, pp. 1272-1277, 2005.

[46] A. L. Bartels, B. M. de Jong, N. Giladi et al., "Striatal dopa and glucose metabolism in PD patients with freezing of gait," Movement Disorders, vol. 21, no. 9, pp. 1326-1332, 2006.

[47] S. L. Naismith, J. M. Shine, and S. J. G. Lewis, "The specific contributions of set-shifting to freezing of gait in Parkinson's disease," Movement Disorders, vol. 25, no. 8, pp. 1000-1004, 2010.

[48] C. H. Williams-Gray, A. Hampshire, R. A. Barker, and A. M. Owen, "Attentional control in Parkinson's disease is dependent on COMT val 158 met genotype," Brain, vol. 131, no. 2, pp. 397-408, 2008.

[49] A. Hampshire and A. M. Owen, "Fractionating attentional control using event-related fMRI," Cerebral Cortex, vol. 16, no. 12, pp. 1679-1689, 2006.

[50] K. Kompoliti, C. G. Goetz, S. Leurgans, M. Morrissey, and I. M. Siegel, "On freezing in Parkinson's disease: resistance to visual cue walking devices," Movement Disorders, vol. 15, no. 2, pp. 309-312, 2000.

[51] R. Cunnington, R. Iansek, and J. L. Bradshaw, "Movementrelated potentials in Parkinson's disease: external cues and attentional strategies," Movement Disorders, vol. 14, no. 1, pp. 63-68, 1999.

[52] R. Chee, A. Murphy, M. Danoudis, N. Georgiou-Karistianis, and R. Iansek, "Gait freezing in Parkinson's disease and the stride length sequence effect interaction," Brain, vol. 132, no. 8, pp. 2151-2160, 2009.

[53] G. Chari, P. J. Shaw, and A. Sahgal, "Nonverbal visual attention, but not recognition memory or learning, processes are impaired in motor neurone disease," Neuropsychologia, vol. 34, no. 5, pp. 377-385, 1996.

[54] J. Gottlieb and M. E. Goldberg, "Activity of neurons in the lateral intraparietal area of the monkey during an antisaccade task," Nature Neuroscience, vol. 2, no. 10, pp. 906-912, 1999.

[55] K. D. Powell and M. E. Goldberg, "Response of neurons in the lateral intraparietal area to a distractor flashed during the delay period of a memory-guided saccade," Journal of Neurophysiology, vol. 84, no. 1, pp. 301-310, 2000.

[56] C. W. Wallesch and C. Papagno, "Subcortical aphasia," in Aphasia, F. C. Rose, R. Whurr, and M. Wyke, Eds., pp. 257287, Whurr, London, UK, 1988.

[57] J. L. Cummings, "Anatomic and behavioral aspects of frontalsubcortical circuits," Annals of the New York Academy of Sciences, vol. 769, pp. 1-13, 1995.

[58] C. J. Stam, S. L. Visser, A. A. W. Op de Coul et al., "Disturbed frontal regulation of attention in Parkinson's disease," Brain, vol. 116, no. 5, pp. 1139-1158, 1993. 


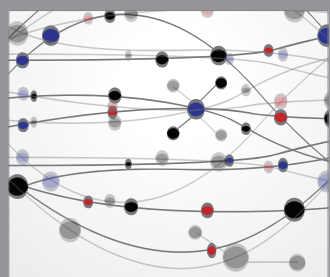

The Scientific World Journal
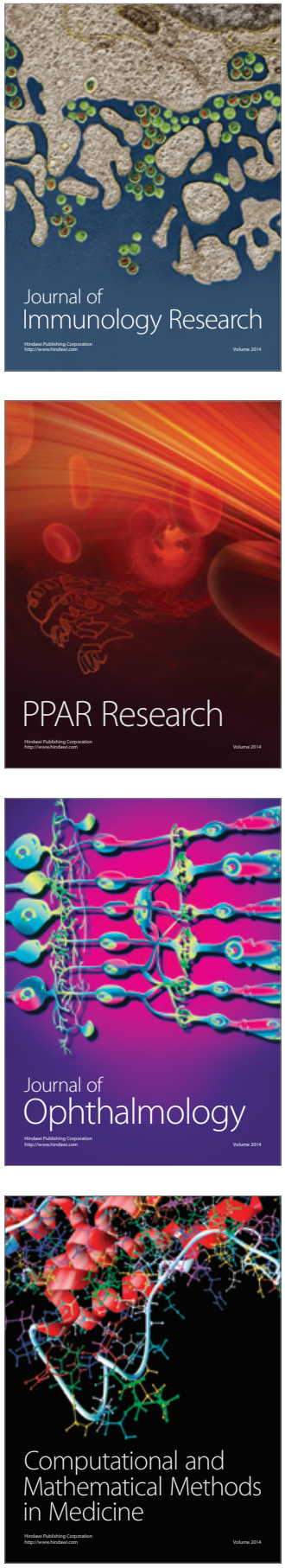

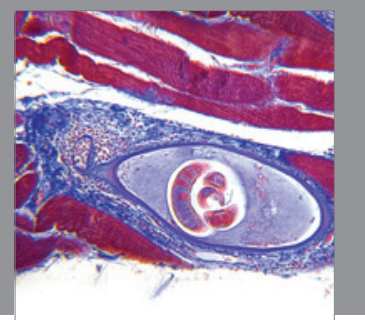

Gastroenterology

Research and Practice


\section{Hindawi}

Submit your manuscripts at

http://www.hindawi.com
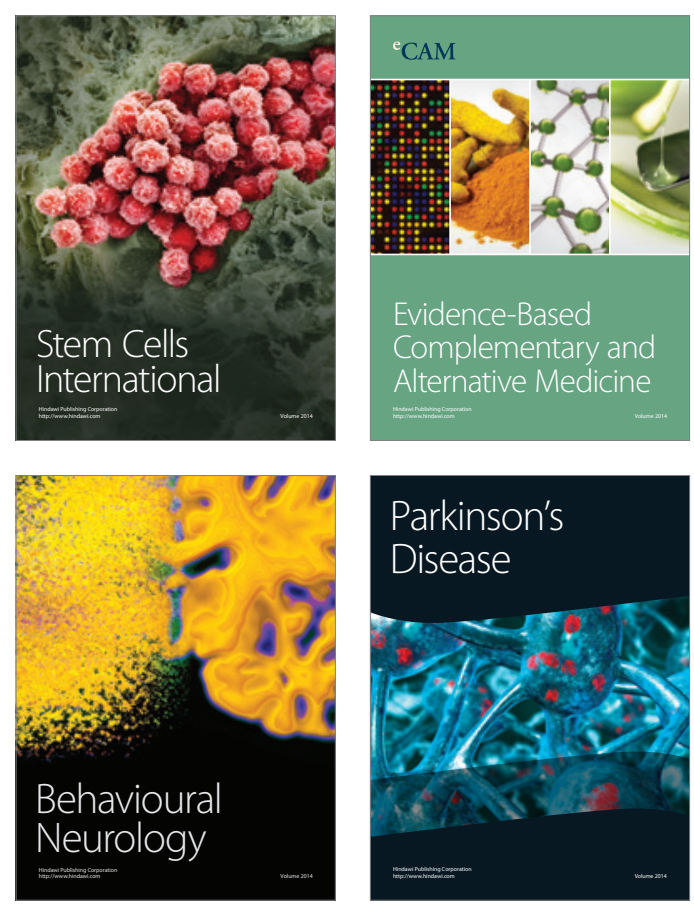

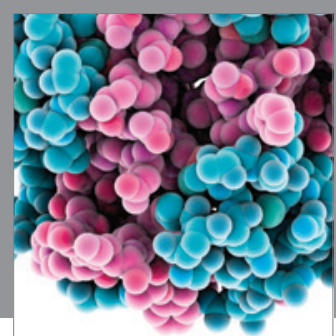

Journal of
Diabetes Research

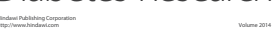

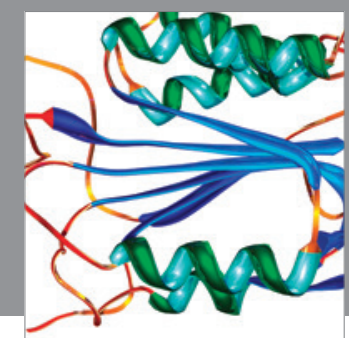

Disease Markers
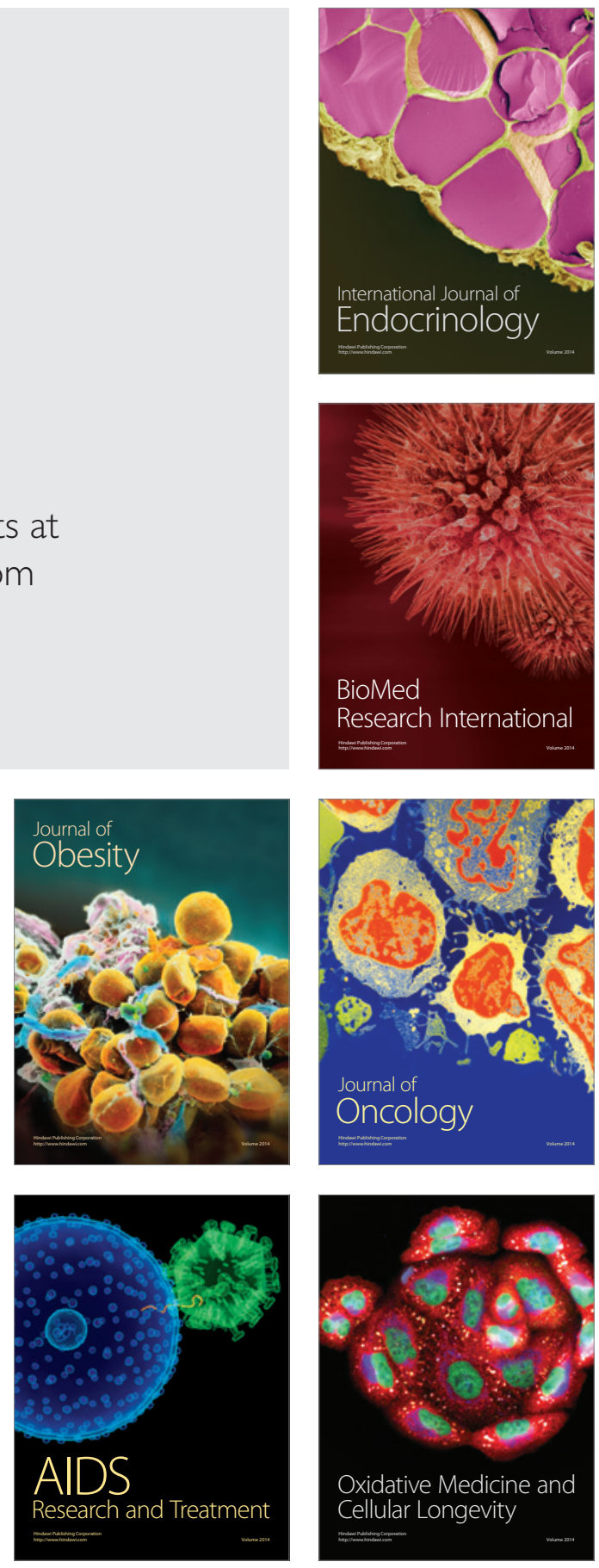